\title{
ANÁLISE ACERCA DAS COMPETÊNCIAS NECESSÁRIAS PARA A ATUAÇÃO PROFISSIONAL DO GESTOR ESPORTIVO
}

\author{
Yves de Holanda Batista de Miranda \\ Universidade de Pernambuco, Recife, Pernambuco, Brasil \\ Marcos Antônio Barros Filho \\ Universidade do Porto, Distrito de Porto, Porto, Portugal \\ Victor Henrique Rodrigues Silva \\ Universidade de Pernambuco, Recife, Pernambuco, Brasil \\ Juliett de Medeiros Correia Figueirêdo \\ Universidade de Pernambuco, Recife, Pernambuco, Brasil \\ Carlos Augusto Mulatinho de Queiroz Pedroso \\ Universidade de Pernambuco, Recife, Pernambuco, Brasil
}

\begin{abstract}
Resumo
O gestor esportivo é desafiado a dirigir organizações em constantes mudanças, devido às ações e às interações de seus agentes e a suas particularidades em diferentes contextos, o que mostra a necessidade de competências específicas para sua atuação. Objetivou-se analisar as competências para a atuação do gestor esportivo à luz da literatura científica. Tratou-se de uma revisão sistemática descritiva, nas bases de dados SPORTDiscus, SCOPUS e Web of Science, e seis artigos foram incluídos para análise. Foram observadas diversas competências necessárias para a atuação, destacando-se o domínio das técnicas de gestão, o gerenciamento dos recursos humanos e as atitudes de liderança. Ressalta-se a necessidade de mais estudos na área com o objetivo de qualificar a formação do gestor esportivo.
\end{abstract}

Palavras-chave: Competência profissional. Área de atuação profissional. Organização e administração.

\section{Introdução}

O aumento da complexidade do fenômeno esportivo, a partir do desenvolvimento da indústria do esporte e da globalização, indica a necessidade de evolução dos processos de gestão. Sendo assim, estes são assuntos cada vez mais debatidos na literatura mundial, principalmente quando associados à necessidade de profissionalização na área. As discussões acerca do desenvolvimento da gestão do esporte apontam para o crescimento da temática como uma área de estudo, a determinar a necessidade de formações específicas para a atuação nesse âmbito (CHELLADURAI, 1992; PITTS, 2001; PIRES; SARMENTO, 2001; ROCHA; BASTOS, 2011). 
A qualificação para a tomada de decisões eficientes e eficazes, no processo de gestão das organizações esportivas que estão inseridas em diferentes contextos, passa pela formação e pela experiência dos gestores esportivos na busca do desenvolvimento de competências específicas (JOAQUIM; BATISTA; CARVALHO, 2011; MELLO; SILVA, 2013). Essa questão é recorrente, visto que esse profissional, por ser o principal responsável pelo gerenciamento de organizações, deve apresentar diversos conhecimentos, referentes a administração, economia, marketing, legislação e política (BASTOS, 2003).

Contudo, as discussões sobre competências profissionais ainda são marcadas pela diversidade e pela falta de consenso sobre quais são e qual é o seu conceito. Para Fleury e Fleury (2001), as competências ultrapassam as limitações do próprio cargo e são definidas como "um saber agir responsável e reconhecido, que implica mobilizar, integrar, transferir conhecimentos, recursos e habilidades, que agreguem valor econômico à organização e valor social ao indivíduo". Além disso, para os autores, são consideradas competências profissionais o saber agir, mobilizar recursos, comunicar, aprender, engajar-se e comprometer-se, assumir responsabilidades e ter visão estratégica.

$\mathrm{Na}$ administração, Chiavenato (2007) considera como competências fundamentais para o administrador: conhecimento (saberes), habilidades (saber fazer), julgamento (saber analisar) e atitude (saber fazer acontecer). Além disso, essas competências estão apoiadas nas habilidades conceituais, técnicas e humanas. Para Drucker (2010), o administrador deve ser eficaz na tomada de decisões, ser bem-sucedido nas decisões sobre pessoas, comunicar-se bem dentro e fora da organização, usar adequadamente controles e medições, ser competente em orçamentos e planejamentos e no uso das modernas ferramentas e conceitos da tecnologia da informação. Para além do entendimento das competências, é preciso compreender que elas são necessárias para que o gestor, o recurso básico de toda empresa, cumpra com suas funções de forma qualificada, identifique as necessidades e esteja sempre em busca de alcançar os objetivos da organização (DRUCKER, 2010).

Em específico na gestão do esporte, as técnicas de gestão, a programação esportiva, a administração de empresas, o planejamento, a organização, a execução, o controle, a comunicação e a tomada de decisão já foram elencadas como competências para a atuação na área em diferentes organizações esportivas (BARCELONA; ROSS, 2004; JOAQUIM; BATISTA; CARVALHO, 2011).

Para superar o desafio de dirigir organizações que estão em constantes mudanças, o gestor esportivo deve apresentar uma gama de competências específicas para atuar na área, ratificando a importância de estudos que busquem verificar esses conhecimentos para auxiliar no desenvolvimento de processos competentes de gestão e na qualificação das formações na área. Portanto, o estudo em questão teve como objetivo analisar as competências para a atuação profissional do gestor esportivo a partir da produção científica sobre o tema.

\section{Métodos}

O método de revisão sistemática descritiva foi escolhido para esta pesquisa por possibilitar um resumo textual das características e das informações relevantes do estudo (DE-LATORRE-UGARTE-GUANILO; TAKAHASHI; BERTOLOZZI, 2011). Ademais, a revisão sistemática mostra-se como uma nova metodologia a ser utilizada nas ciências do movimento humano, pois é considerada um método útil que sintetiza as informações de forma qualificada e oferece novos direcionamentos (GOMES; CAMINHA, 2014).

A pesquisa foi realizada nas bases de dados eletrônicas SPORTDiscus, SCOPUS e Web of Science, por se tratarem de bases de dados com grande alcance e foco na área investigada. Os descritores utilizados nas buscas foram definidos a partir da leitura do título e das palavras-chave de artigos de referência na temática e foram divididos em três grupos, com 
cruzamento intra e intergrupo a partir das ferramentas de busca avançada (Quadro 1). Além disso, a busca considerou apenas estudos publicados entre os anos de 2005 e 2015.

Quadro 1 - Grupos de descritores e seus cruzamentos a partir das ferramentas de busca avançada

\begin{tabular}{|c|c|c|c|c|}
\hline GRUPO 1 & - & GRUPO 2 & - & GRUPO 3 \\
\hline $\begin{array}{c}\text { "Sport Management" } \\
\text { OR } \\
\text { "Sport Administra- } \\
\text { tion" } \\
\text { OR } \\
\text { "Management" } \\
\text { OR } \\
\text { "Administration" }\end{array}$ & $A N D$ & $\begin{array}{c}\text { "Sport Managers" } \\
\text { OR } \\
\text { "Sport Administrator" } \\
\text { OR } \\
\text { "Managers" } \\
\text { OR } \\
\text { "Sport Directors" } \\
\text { OR } \\
\text { "Directors" }\end{array}$ & $A N D$ & $\begin{array}{c}\text { "Competencies" } \\
\text { OR } \\
\text { "Management Com- } \\
\text { petencies" } \\
\text { OR } \\
\text { "Responsibilities"'" }\end{array}$ \\
\hline
\end{tabular}

Fonte: Elaborado pelos autores (2016).

A revisão foi realizada por pares, por meio da qual foram encontrados 151 estudos na SPORTDiscus, 153 na SCOPUS e 1 na Web of Science. Para a seleção dos estudos, foi considerado como critério de inclusão: a) artigos referentes às competências necessárias para a atuação profissional do gestor esportivo em diferentes organizações. Como critério de exclusão, foram considerados: a) artigos de revisão; b) artigos de opinião; c) ensaios. A partir da leitura do título e do resumo de todos os artigos, 299 estudos foram excluídos por não estarem de acordo com o critério de inclusão a), apresentando-se a priori 12 artigos como elegíveis. Após a leitura na íntegra dos estudos, cinco artigos foram excluídos por não estarem de acordo com o critério de inclusão a) e um artigo pelo critério de exclusão b). O procedimento de seleção pode ser visto na Figura 1.

Figura 1 - Fluxograma da seleção dos estudos incluídos na revisão

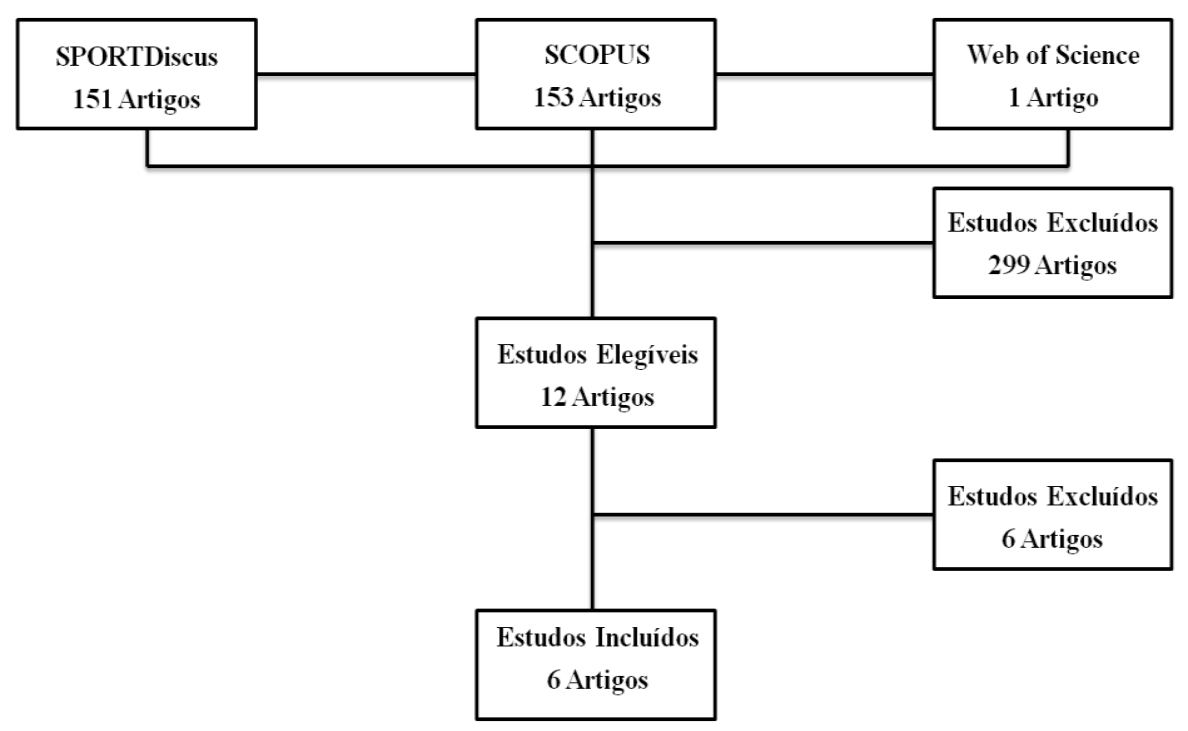

Fonte: Elaborado pelos autores (2016).

Para uma melhor análise dos resultados dos estudos selecionados, as informações sobre autores, país e ano de publicação, objetivo do estudo, materiais e métodos e principais resultados foram organizados em formato de quadros (Quadro 2 e Quadro 3). Além disso, a 
análise e a discussão dos resultados foram realizadas a partir da categorização dos estudos nas seções "Competências do gestor esportivo em contexto geral" e "Competências do gestor esportivo em contexto específico", apresentadas na Tabela 1.

\section{Resultados e discussão}

No Quadro 2, são apresentados os artigos selecionados a partir das informações, de forma sintetizada e cronológica, sobre os autores, país e ano de publicação, objetivo do estudo e materiais e métodos.

Quadro 2 - Dados extraídos dos estudos incluídos na revisão

\begin{tabular}{|c|c|c|}
\hline $\begin{array}{c}\text { Autores } \\
\text { (país - ano) }\end{array}$ & Objetivo do estudo & Materiais e métodos \\
\hline $\begin{array}{l}\text { Tripolitsioti et al. } \\
\text { (Grécia - 2007) }\end{array}$ & $\begin{array}{l}\text { Construir um instrumento } \\
\text { válido e confiável para deter- } \\
\text { minar as competências neces- } \\
\text { sárias para gerir os clubes de } \\
\text { saúde e fitness e instalações } \\
\text { internas das organizações } \\
\text { juvenis e desportivas dos } \\
\text { municípios gregos. }\end{array}$ & $\begin{array}{l}\text { Realizou-se um estudo-piloto com } 101 \text { diretores de clubes } \\
\text { e de instalações esportivas internas de saúde e fitness, no } \\
\text { qual cada competência foi analisada com uma escala Liker } \\
\text { de } 5 \text { pontos. No fim, o questionário, adaptado de Toh } \\
\text { (1997), apresenta } 72 \text { declarações de competências. Os } \\
\text { dados foram inseridos no software Microsoft Excel } 2003 \text { e } \\
\text { depois convertidos para o pacote estatístico SPSS 13.0. As } \\
\text { estatísticas descritivas como médias, desvios padrão, ran- } \\
\text { kings das declarações de competência e os percentuais de } \\
\text { frequência foram usadas para obter informações a partir da } \\
\text { análise de dados. }\end{array}$ \\
\hline $\begin{array}{l}\text { Ball et al. } \\
\text { (Estados Unidos } \\
\text { da América - } \\
\text { 2008) }\end{array}$ & $\begin{array}{l}\text { Identificar as competências de } \\
\text { liderança consideradas mais } \\
\text { importantes para diretores de } \\
\text { lazer no sistema Universidade } \\
\text { de Wisconsin. }\end{array}$ & $\begin{array}{l}\text { Participaram da coleta de dados } 10 \text { diretores de recreação } \\
\text { universitária do sistema de Universidade de Wisconsin } \\
\text { que preferiram se comunicar via e-mail. A obtenção dos } \\
\text { dados foi realizada a partir do método Delphi, com } 3 \text { roda- } \\
\text { das. Na segunda e terceira rodadas, para a análise das } \\
\text { competências, foi utilizado um questionário com escala } \\
\text { Likert. }\end{array}$ \\
\hline $\begin{array}{l}\text { Ko; Henry; Kao } \\
\text { (Taiwan - 2011) }\end{array}$ & $\begin{array}{l}\text { a) Desenvolver um instrumen- } \\
\text { to de pesquisa específico para } \\
\text { o contexto de Taiwan; b) In- } \\
\text { vestigar a percepção dos ges- } \\
\text { tores desportivos e acadêmi- } \\
\text { cos sobre as competências } \\
\text { importantes para o sucesso } \\
\text { esportivo; c) Identificar e } \\
\text { explicar as diferenças signifi- } \\
\text { cativas entre as competências } \\
\text { identificadas pelos gestores e } \\
\text { acadêmicos. }\end{array}$ & $\begin{array}{l}\text { Para o desenvolvimento do questionário dentro da realida- } \\
\text { de específica de Taiwan, foi realizada uma revisão sistemá- } \\
\text { tica, uma análise do currículo de } 13 \text { instituições de ensino } \\
\text { superior em Taiwan que fornecem programas de gestão do } \\
\text { desporto e a utilização do método Delphi com } 27 \text { especia- } \\
\text { listas da gestão do desporto, tudo com o objetivo de elen- } \\
\text { car competências para a construção do questionário. Após } \\
\text { a definição de } 70 \text { competências, com suas definições, cada } \\
\text { uma era classificada por uma escala Likert, de } 1 \text { (nada } \\
\text { importante) a } 7 \text { (extremamente importante). Do universo } \\
\text { solicitado, } 205 \text { gestores e } 83 \text { acadêmicos responderam ao } \\
\text { questionário. A análise das respostas foi realizada por } \\
\text { análise fatorial de componentes principais, com análise de } \\
\text { variância com o uso de MANOVA e ANOVA. }\end{array}$ \\
\hline $\begin{array}{l}\text { Retar; Plevnik; } \\
\text { Kolar } \\
\text { (Eslovênia - } \\
\text { 2013) }\end{array}$ & $\begin{array}{l}\text { Formular uma gama de com- } \\
\text { petências relevantes, variá- } \\
\text { veis, e compará-las com mo- } \\
\text { delos similares }\end{array}$ & $\begin{array}{l}\text { A coleta dos dados foi realizada através de questionário } \\
\text { eletrônico com escala de } 1 \text { (não importante) a } 6 \text { (muito } \\
\text { importante) para a avaliação da importância das competên- } \\
\text { cias ditas pelos gestores. Para a análise das características } \\
\text { socioeconômicas dos entrevistados, foi utilizada estatística } \\
\text { descritiva, com os dados sendo analisados no software } \\
\text { SPSS. O questionário foi enviado a } 150 \text { gestores, mas } \\
\text { respondido apenas por } 85 \text { indivíduos. }\end{array}$ \\
\hline
\end{tabular}




\begin{tabular}{|c|c|c|}
\hline $\begin{array}{l}\text { Eksteen; Malan; } \\
\text { Lotriet } \\
\text { (África do Sul - } \\
\text { 2013) }\end{array}$ & $\begin{array}{l}\text { Comparar as competências } \\
\text { gerenciais de alguns gestores } \\
\text { de clubes esportivos à medida } \\
\text { que são percebidos por alguns } \\
\text { treinadores de clubes esporti- } \\
\text { vos na província Noroeste da } \\
\text { África do Sul. }\end{array}$ & $\begin{array}{l}\text { Para a coleta dos dados foi utilizado um questionário adap- } \\
\text { tado de Vosloo (2007), um para os gestores e outro para os } \\
\text { treinadores, ambos contendo duas seções. Foram obtidas } \\
63 \text { respostas, mas consideradas } 60 \text {, para manter a igualdade } \\
\text { de } 30 \text { respostas de gestores e } 30 \text { de treinadores. A estatísti- } \\
\text { ca descritiva de cada variável foi calculada seguida por um } \\
\text { teste } t \text { independente para determinar a diferença entre o } \\
\text { que os gestores perceberam como as competências neces- } \\
\text { sárias para gerir um clube desportivo e quais os treinadores } \\
\text { perceberam. }\end{array}$ \\
\hline $\begin{array}{l}\text { Carvalho } \\
\text { (Portugal - 2013) }\end{array}$ & $\begin{array}{l}\text { Definir o perfil funcional de } \\
\text { competências do técnico supe- } \\
\text { rior de desporto inserido em } \\
\text { municípios do distrito de Vi- } \\
\text { seu }\end{array}$ & $\begin{array}{l}\text { Estruturado em duas fases: extensiva e intensiva. Na fase } \\
\text { extensiva, foi realizada uma pesquisa descritiva explorató- } \\
\text { ria, com a utilização de um questionário com escala Likert } \\
\text { de seis pontos, com resposta de } 50 \text { gestores, em que os } \\
\text { dados foram tratados pelo programa SPSS versão 17.0. A } \\
\text { fase intensiva é de natureza interpretativa, com a utilização } \\
\text { de entrevista estruturada com dez questões de resposta } \\
\text { aberta, para } 10 \text { gestores. A análise dos dados da entrevista } \\
\text { foi realizada por análise de conteúdo segundo Bardin } \\
\text { (2004), através do programa NVivo7. }\end{array}$ \\
\hline
\end{tabular}

Fonte: Elaborado pelos autores (2016).

A partir da análise do Quadro 2, é possível verificar que todos os artigos incluídos para a análise apresentaram em algum momento da pesquisa o uso do questionário como método para a coleta de dados (TRIPOLITSIOTI et al. 2007; BALL et al. 2008; KO; HENRY; KAO, 2011; CARVALHO, 2013; RETAR; PLEVNIK; KOLAR, 2013; EKSTEEN; MALAN; LOTRIET, 2013). Além disso, dois estudos utilizaram-se também do método Delphi na coleta de informações (KO; HENRY; KAO, 2011; EKSTEEN; MALAN; LOTRIET, 2013). Esse método é utilizado na busca de um consenso de opiniões de um grupo específico de indivíduos a respeito de determinado assunto, quando há carência de informações ou quando se quer estimular o surgimento de novas ideias (WRIGHT; GIOVINAZZO, 2000).

Observa-se uma heterogeneidade na análise das produções de acordo com a localidade em que os estudos ocorreram. Foram encontradas pesquisas realizadas em quatro continentes diferentes, sendo três delas no continente europeu (TRIPOLITSIOTI et al. 2007; CARVALHO, 2013; RETAR; PLEVNIK; KOLAR, 2013), uma no americano (BALL et al., 2008), uma no asiático (KO; HENRY; KAO, 2011) e uma no africano (EKSTEEN; MALAN; LOTRIET, 2013). Ao contrário do que foi visto no estudo de Joaquim, Batista e Carvalho (2011), pode-se observar uma produção no continente africano, o que pode indicar o início da realização de pesquisas sobre essa temática nessa localidade. Além disso, o levantamento de apenas um estudo no continente americano pode indicar uma diminuição no interesse dos pesquisadores sobre o perfil de competências de gestores esportivos, informação diferente do que foi encontrado em Joaquim, Batista e Carvalho (2011).

Para que haja um melhor entendimento dos estudos selecionados, os principais resultados de cada um foram expostos no Quadro 3. 
Quadro 3 - Principais resultados dos estudos incluídos na revisão

\begin{tabular}{|c|c|}
\hline $\begin{array}{c}\text { Título } \\
\text { (Autores / País - Ano) }\end{array}$ & Principais Resultados \\
\hline $\begin{array}{l}\text { The management competen- } \\
\text { cies of the directors of youth } \\
\text { centres and indoor facilities } \\
\text { in the municipalities } \\
\text { (TRIPOLITSIOTI, et al. / } \\
\text { Grécia - 2007) }\end{array}$ & $\begin{array}{l}\text { A partir da construção e da aplicação do questionário, oito competências básicas } \\
\text { foram identificadas: técnicas de gestão, ciências do esporte, gestão de eventos, } \\
\text { relações públicas, habilidades de pesquisa/informática, gestão de instalações, de } \\
\text { governança e de prevenção/segurança contra acidentes. As competências encon- } \\
\text { tradas estão de acordo com os resultados de outros estudos pesquisados na litera- } \\
\text { tura. }\end{array}$ \\
\hline $\begin{array}{l}\text { Leadership competencies of } \\
\text { university recreational di- } \\
\text { rectors in Wisconsin } \\
\text { (BALL et al./ Estados Uni- } \\
\text { dos da América - 2008) }\end{array}$ & $\begin{array}{l}\text { A partir da utilização do método Delphi, verificou-se que os diretores de recrea- } \\
\text { ção consideraram como competências importantes ligadas à liderança: compro- } \\
\text { misso e integridade, habilidades de comunicação, habilidades na gestão de orça- } \\
\text { mentos, gestão de pessoas e adaptabilidade às mudanças. Todas as competências } \\
\text { citadas puderam ser vistas na revisão de literatura realizada, inclusive em outras } \\
\text { áreas diferentes da recreação, com exceção da gestão do orçamento. }\end{array}$ \\
\hline $\begin{array}{l}\text { The perceived importance } \\
\text { of sport management com- } \\
\text { petencies by academics and } \\
\text { practitioners in the cultur- } \\
\text { al/industrial context of Tai- } \\
\text { wan } \\
\text { (KO; HENRY; KAO / Tai- } \\
\text { wan - 2011) }\end{array}$ & $\begin{array}{l}\text { Os gestores desportivos e acadêmicos determinaram as técnicas de gestão, teoria } \\
\text { e fundamentos relacionados ao desporto, desenvolvimento e prestação de servi- } \\
\text { ços, capacidade de aprendizagem e língua estrangeira, finanças e economia como } \\
\text { as competências mais importantes para atuação profissional. Chamou-se a aten- } \\
\text { ção para o aparecimento da competência "língua estrangeira", por não ter sido } \\
\text { relatada em outros estudos. Isso pode ser explicado pelo contexto histórico políti- } \\
\text { co recente de Taiwan, de desenvolvimento de negócios. Além disso, algumas } \\
\text { competências foram percebidas de forma diferente entre os gestores e os acadê- } \\
\text { micos, mas isso não quer dizer que sejam visões opostas. }\end{array}$ \\
\hline $\begin{array}{l}\text { Key competences of Slove- } \\
\text { nian sport managers } \\
\text { (RETAR; PLEVNIK; KO- } \\
\text { LAR / Eslovênia - 2013) }\end{array}$ & $\begin{array}{l}\text { Observou-se que } 82,3 \% \text { dos entrevistados estavam empregados no setor público e } \\
\text { em instituições da sociedade civil, enquanto os demais estavam no setor privado. } \\
\text { Além disso, } 43,5 \% \text { dos gestores chegaram ao nível superior de ensino, dos quais } \\
5,9 \% \text { eram doutores e } 8,2 \% \text { eram mestres. Na determinação das principais com- } \\
\text { petências para a profissão, a cooperação com os recursos humanos da empresa foi } \\
\text { considerada a principal referente às competências gerais e o desenvolvimento de } \\
\text { um ambiente de trabalho positivo referente às específicas. }\end{array}$ \\
\hline $\begin{array}{l}\text { Management competencies } \\
\text { of sport club managers in } \\
\text { the North-West Province, } \\
\text { South Africa } \\
\text { (EKSTEEN; MALAN ; } \\
\text { LOTRIET / África do Sul - } \\
\text { 2013) }\end{array}$ & $\begin{array}{l}\text { Verificou-se que } 71,5 \% \text { dos entrevistados são homens e que } 42 \% \text { têm idade entre } \\
35 \text { e } 44 \text { anos. Além disso, } 60 \% \text { têm ensino superior completo. Das } 25 \text { competên- } \\
\text { cias consideradas para análise no questionário, todas obtiveram um valor médio } \\
\text { maior por parte dos treinadores. Sobre as competências, } 18 \text { apresentaram diferen- } \\
\text { ça significativa na percepção de importância entre os gestores e os treinadores, } \\
\text { verificando-se que os treinadores não têm percebido o trabalho dos gestores dos } \\
\text { clubes sendo executado de forma qualificada. }\end{array}$ \\
\hline $\begin{array}{l}\text { Perfil funcional de compe- } \\
\text { tências dos gestores de des- } \\
\text { porto - Estudo de caso dos } \\
\text { técnicos superiores de des- } \\
\text { porto do distrito de Viseu } \\
\text { (CARVALHO / Portugal - } \\
\text { 2013) }\end{array}$ & $\begin{array}{l}\text { Na fase extensiva, os técnicos superiores de desporto definiram a docência / } \\
\text { lecionação como a dimensão mais valorizada na relação competência / função. } \\
\text { Na fase intensiva, entre as três categorias definidas previamente para a análise de } \\
\text { conteúdo (fontes de conhecimento, áreas de intervenção e representação de com- } \\
\text { petências), a mais citada foi áreas de intervenção. Além disso, a experiência e a } \\
\text { formação contínua são as fontes de conhecimento mais valorizadas pelos técni- } \\
\text { cos, e o planejamento, a concepção de projetos desportivos e a gestão de recursos } \\
\text { logísticos e humanos como suas principais áreas de atuação. }\end{array}$ \\
\hline
\end{tabular}

Fonte: Elaborado pelos autores (2016). 
A divisão da análise dos estudos em duas categorias foi realizada com o objetivo de melhor discutir sobre a temática abordada e os estudos encontrados, a fim de relacioná-los também com outros estudos da área.

Tabela 1 - Categorização dos estudos incluídos na revisão

\begin{tabular}{lll}
\hline CATEGORIA & \multicolumn{2}{l}{ QUANTIDADE DE ESTU- } \\
& DOS & \\
\hline Competências do gestor esportivo em contexto geral & 2 \\
Competências do gestor esportivo em contexto específico & 4 \\
\hline TOTAL & 6 \\
\hline
\end{tabular}

Fonte: Elaborado pelos autores (2016).

Nota-se que há a predominância de mais estudos que se propuseram a pesquisar em organizações específicas, como clubes esportivos (EKSTEEN; MALAN; LOTRIET, 2013), no contexto municipal (TRIPOLITSIOTI et al., 2007; CARVALHO, 2013) e recreativo universitário (BALL et al., 2008). Em contrapartida, dois estudos (KO; HENRY; KAO, 2011; RETAR; PLEVNIK; KOLAR, 2013) abordaram as competências no contexto geral da gestão do esporte.

\section{Competências do gestor esportivo em contexto geral}

$\mathrm{Na}$ busca de compreender as competências necessárias para a atuação na gestão do esporte, é importante entender que cada ambiente está sujeito a necessidades que são específicas do local onde a organização esportiva se encontra (KO; HENRY; KAO, 2011). Esse elemento pode justificar o fato de diferentes competências terem sido consideradas importantes nos estudos de Ko, Henry e Kao (2011) e Retar, Plevnik e Kolar (2013), havendo pouca similaridade entre as competências encontradas.

$\mathrm{Na}$ realidade de Taiwan, foram apresentadas como competências do gestor esportivo técnicas de gestão, teoria e fundamentos relacionados ao desporto, desenvolvimento e prestação de serviços, capacidade de aprendizagem e língua estrangeira, finanças, economia e habilidades analíticas, comunicação, consciência política, de contabilidade e gestão de risco, gestão da informação e da tecnologia e conhecimento sobre a teoria da gestão, diferente da realidade vista na Eslovênia. No país europeu, o desenvolvimento de um trabalho positivo, trabalhar como uma autoridade profissional e moral, organizar e delegar tarefas, apresentar ideias inovadoras, cooperar com as pessoas e usar o conhecimento adquirido na prática foram apresentadas como competências para atuar nos cargos de gestão. Percebe-se que não há um consenso entre os dois estudos, sendo possível perceber apenas uma congruência em ambas pesquisas referente à consciência política e à postura de trabalhar de forma profissional e moral.

$\mathrm{Na}$ formação de profissionais qualificados para trabalhar na gestão do esporte, tanto em nível de graduação como de pós-graduação, a Commission on Sport Management Accreditation (COSMA) estabelece um modelo de currículo que é utilizado por vários centros de ensino no mundo, abordando cinco grandes áreas: Fundamentos do Esporte, Fundamentos da Gestão do Esporte, Funções da Gestão do Esporte, Ambiente da Gestão do Esporte e Experiências Integrativas e Plano de Carreira. Nessas áreas, é possível enfatizar o estudo de temas como marketing esportivo, comunicação, economia e finanças esportivas, aspectos legais e éticos do esporte, conceitos de gestão, governança e política, esporte internacional, operações esportivas e técnicas avançadas, conhecimentos esses necessários para a atuação do gestor 
esportivo em diferentes contextos, ao mesmo tempo em que são compreendidos como possíveis competências desse profissional.

\section{Competências do gestor esportivo em contexto específico}

No contexto dos clubes esportivos, dentro da realidade sul-africana, o estudo de Eksteen, Malan e Lotriet (2013) verificou que os técnicos do clube deram mais importância do que os gestores à maioria das competências elencadas, como gestão da informação, gerenciamento de procedimentos de escritório, abordagem de questões éticas e legais, conhecimento de problemas legais, entre outros. Esses achados não foram encontrados em outra realidade quando comparados com o estudo de Horch \& Schütte (2003), realizado na Alemanha, no qual os gestores de clubes esportivos e de federações consideraram como competências importantes para a atuação na área a comunicação interpessoal e a gestão de pessoas, além de incluir aspectos da administração de empresas, como financiamento, orçamento, patrocínio e gestão de eventos.

Essas informações também são diferentes do que foi encontrado por Tripolitsioti et al. (2007), que apontaram as técnicas de gestão, conhecimento sobre gestão de eventos, ciências do esporte, relações públicas, habilidades tecnológicas/pesquisa, gestão de instalações, de governança e de cuidados na prevenção de lesão de atletas como sendo as competências dos gestores de clubes e instalações esportivas.

Referente à atuação no âmbito recreacional, Ball et al. (2008) apontaram que o gestor esportivo deve apresentar como competências relacionadas à liderança o compromisso e a integridade, habilidades de comunicação e gestão de orçamentos, gestão de pessoas e adaptabilidade às mudanças. Já para Barcelona e Ross (2004), o profissional da gestão nessa área de atuação deve apresentar competências necessárias acerca das técnicas de gestão, sobre programação esportiva, administração de empresas e conhecimentos teóricos da área.

No setor público, o estudo de Carvalho (2013) apontou que a lecionação/docência e o planejamento/organização são as principais competências dos técnicos superiores de desporto necessárias para atuar na gestão pública. Em comparação com o estudo de Tavares (2010), é observada uma diferença, pois, a partir da coleta de dados do grupo focal com gestores públicos relacionados à área de esportes de municípios da Grande Belo Horizonte, foram definidas cinco competências consideradas essenciais para a atuação na área: conhecimento acumulado, visão estratégica, relacionamento, pró-atividade, responsabilidade.

O levantamento dessas competências, tanto gerais quanto específicas, oferece subsídios para que se tenha uma noção do que esse profissional precisa ser e saber para que desempenhe bem suas funções. Entretanto, é sabido que a complexidade existente nos processos de gestão não faz desse levantamento uma cartilha desprovida de mudanças, pois, como é afirmado por Zarifian (1996), as relações de trabalho não são estáticas, o que faz com que as competências também não o sejam. O processo de formação do gestor deve ser constante, para que atualize seus conhecimentos e permita-se estar disponível para as mudanças do mundo globalizado.

\section{Conclusões}

Concluiu-se com a realização do estudo que o gestor do esporte utiliza-se de diferentes competências na sua atuação em busca do sucesso, destacando-se o domínio das técnicas de gestão, o gerenciamento dos recursos humanos e as atitudes de liderança.

Contudo, devido à complexidade do esporte e à dinamicidade dos processos de gestão, talvez sejam observadas em outros estudos competências que são de fundamental importância nessa atuação profissional, mas que não foram elencadas nesta revisão. Isso pode ser ocasio- 
nado também pela especificidade sociocultural de cada local a ser investigado. Além disso, chama-se atenção para o fato de competências relacionadas ao planejamento e ao controle de atividades, princípios bases para a eficiência e a eficácia nos processos de gestão, assim como os atos de organizar e dirigir, não terem sido vistas com mais frequência, o que pode ser um fator negativo que indique que os profissionais não consideram esses conhecimentos como importantes, negligenciando a atuação profissional.

Em contraponto ao processo de globalização visto no esporte, tratado de forma espetacularizada e rendimentalizada, percebe-se que os gestores do esporte não apresentaram as competências necessárias para gerir suas organizações na atualidade. Com isso, percebe-se uma contradição, uma vez que o acesso aos conhecimentos relacionados às competências estão disponíveis.

Por fim, o fato de a pesquisa ter sido realizada apenas em três bases de dados pode ter limitado o número de artigos encontrados, assim como os descritores e os critérios de inclusão e exclusão. Novos estudos devem ser realizados de forma a traçar as competências necessárias para atuar na área, incluindo novos ambientes como a gestão de eventos esportivos, a fim de fortalecer a área e obter-se um consenso com relação a esses conhecimentos.

\title{
ANALYSIS OF CORE COMPETENCIES FOR THE SPORTS MANAGER ROLE
}

\begin{abstract}
Sports manager has been challenged to run organizations that are always changing due to their particularities in different contexts as well the actions and interactions between their stakeholders leading to the necessity of specific competencies for the sports manager role in line with the scientific literature. This is an Descriptive Systematic Review based on SPORTDiscus, SCOPUS and Web of Science databases and six papers were included for analysis. Among a diversity of core competencies for sports manager role, it can be highlighted the mastery of administration techniques, Human Resources management and leadership attitudes. It emphasizes the necessity of more studies on the field aiming to qualify the theoretical basis of the Sports Manager.
\end{abstract}

Keywords: Professional Competence. Professional Practice Location. Organization and Administration.

\section{ANÁLISIS SOBRE LAS HABILIDADES NECESARIAS PARA LA PRÁCTICA DEL DIRECTOR DE DEPORTES}

\section{Resumen}

El director deportivo tiene el reto de conducir organizaciones que cambian constantemente debido a las acciones e interacciones de sus agentes y sus peculiaridades en diversos contextos, lo que demuestra la necesidad de habilidades específicas para la actuación de ese profesional. Este estudio tuvo como objetivo analizar las habilidades para el desempeño del Director de Deportes a la luz de la ciencia. Esta fue una revisión sistemática descriptiva, en las bases de datos SPORTDiscus, SCOPUS y Web of Science. Para el análisis fueron incluidos seis artículos. Se observaron diversas habilidades necesarias para la actuación, sobresaliendo el dominio de las técnicas de gestión, gestión de recursos humanos y actitudes de liderazgo. Es indispensable la realización de más estudios en el área para el logro de la formación del director deportivo.

Palabras clave: Habilidad Profesional. Área de actuación Profesional. Organización y Administración. 


\section{Referências}

BALL, J. et al. Leadership competencies of university recreational directors in Wisconsin. Recreational Sports Journal, 32, 2008, p. 3-10.

BARCELONA, B.; ROSS, C. M. An analysis of the perceived competencies of recreational sport administrators. Journal of Park and Recreation Administration, 22, 2004, p. 22-42.

BASTOS, F. C. Administração esportiva: área de estudo, pesquisa e perspectiva no Brasil. Motrivivência, São Cristóvão, v. 20, n. 1, 2003, p. 295-306.

CARVALHO, M. J. Perfil funcional de competências dos gestores de desporto: estudo de caso dos técnicos superiores de desporto do distrito de Viseu. Revista Intercontinental de Gestão Desportiva, v. 3, n. 1, 2013, p. 16-37.

CHELlADURAI, P. Sport management: opportunities and obstacles. Journal of Sport Management, v. 6, n. 3, 1992, p. 215-219.

CHIAVENATO, I. Administração: teoria, processo e prática. 4 ed. Rio de Janeiro: Elsevier, 2007.

COMMISSION ON SPORT MANAGEMENT ACCREDITATION. Accreditation principles manual \& guidelines for self-study preparation. Reston: COSMA, 2016.

DE-LA-TORRE-UGARTE-GUANILO, M. C.; TAKAHASHI, R. F.; BERTOLOZZI, M. R. Revisão sistemática: noções gerais. Revista da Escola de Enfermagem USP, v. 45, n. 5, 2011, p. 1260-1266.

DRUCKER, P. F. Gestão. Rio de Janeiro: Agir, 2010.

EKSTEEN, E.; MALAN, D. D. J.; LOTRIET, R. Management competencies of sport club managers in the North-West Province, South Africa. African Journal for Physical, Health Education, Recreation and Dance, v. 19, n. 4:1, dez. 2013, p. 928-936.

FLEURY, M. T. L.; FLEURY, A. Construindo o conceito de competência. Revista de Administração Contemporânea, Curitiba, 5, 2001, p. 183-196.

GOMES, I. S.; CAMINHA, I. D. O. Guia para estudos de revisão sistemática: uma opção metodológica para as ciências do movimento humano. Movimento, Porto Alegre, v. 20, n. 1, 2014, p. 395-411.

HORCH, H.-D.; SCHÜTTE, N. Competencies of sport managers in German sport clubs and sport federations. Managing Leisure, v. 8, abril 2003, p. 70-84.

JOAQUIM, B. A.; BATISTA, P. M.; CARVALHO, M. J. Revisão sistemática sobre o perfil de competências do gestor esportivo. Movimento, v. 17, n. 1, 2011, p. 255-279.

KO, L.-M.; HENRY, I.; KAO, J. C.-H. The perceived importance of sport management competencies by academics and practitioners in the cultural/industrial context of Taiwan. Managing Leisure, 16. out. 2011, p. 302-317.

MELLO, J. A. C. D.; SILVA, S. A. P. D. S. Competências do gestor de academias esportivas. Motriz, Rio Claro, 19, n. 1, 2013, p. 74-83. 
PIRES, G. M. V. D. S.; LOPES, J. P. S. D. R. Conceito de gestão do desporto. Novos desafios, diferentes soluções. Revista Portuguesa de Ciências do Desporto, v. 1, n. 1, 2001, p. $88-103$.

; SARMENTO, J. P. de R. L. Conceito de Gestão do Desporto:

Novos desafios, diferentes soluções. Revista Portuguesa de Ciências do Desporto, Porto, 2001, v. 1, n. 1, p. 88-103.

PITTS, B. G. Sport management at the millenium: a defining moment. Journal of Sport Management, v. 15, p. 1-9, 2001.

RETAR, I.; PLEVNIK, M.; KOLAR, E. Key Competencies of Slovenian sport managers. Annales Kinesiologiae, v. 4, n. 2, 2013, p. 81-94.

ROCHA, C. M. D.; BASTOS, F. C. Gestão do esporte: definindo a área. Revista Brasileira de Educação Física e Esporte, v. 25, p. 91-103, 2011.

TAVARES, A. L. As competências dos gestores públicos de esporte. Pedro Leopoldo: UNIPEL, 2010.

TRIPOLITSIOTI, A. et al. The management competencies of the directors of youth centres and indoor facilities in the municipalities. Journal Biology Exercise, v. 3, p. 47-58, 2007. WRIGHT, J. T. C.; GIOVINAZZO, R. A. Delphi - Uma ferramenta de apoio ao planejamento prospectivo. Caderno de Pesquisas em Administração, São Paulo, v. 1, n. 12, p. 54-65, 2000.

ZARIFIAN, P. Gestão da e pela competência. In: SEMINÁRIO INTERNACIONAL EDUCAÇÃO PROFISSIONAL, TRABALHO E COMPETÊNCIAS. Anais... Rio de Janeiro, 1996.

Recebido em: 16/11/2016

Revisado em: 03/02/2017

Aprovado em: 29/05/2017

Endereço para correspondência:

miranda95y@gmail.com

Yves de Holanda Batista de Miranda

Universidade de Pernambuco

Escola Superior de Educação Física

Rua Arnóbio Marques, 310

Santo Amaro

50.100-130 -Recife . PE - Brasil 